\title{
AGROMETEOROLOGIA
}

\section{DIFERENÇAS ESTACIONAIS ENTRE VARIÁVEIS MICROCLIMÁTICAS PARA AMBIENTES DE INTERIOR DE MATA, VINHEDO E POSTO METEOROLÓGICO EM JUNDIAÍ (SP) ${ }^{(1)}$}

\author{
JOSÉ LUIZ HERNANDES(2); MÁRIO JOSÉ PEDRO-JÚNIOR ${ }^{(2,3)}$; \\ LUDMILA BARDIN(2)
}

\begin{abstract}
RESUMO
Os estudos de caracterização da variabilidade microclimática são essenciais para avaliação de alternativas silviculturais e manejo de vinhedos. Por essa razão, compararam-se variação estacional da temperatura, umidade relativa do ar e velocidade do vento entre os ambientes: interior de uma mata semidecídua, um vinhedo da variedade Niagara Rosada e um posto meteorológico, em Jundiaí (SP), utilizando-se dados diários obtidos por estações meteorológicas automáticas em agosto de 2000 (inverno), outubro de 2000 (primavera) e janeiro de 2001 (verão). A mata alterou significativamente o microclima em seu interior, diminuindo a temperatura máxima em $1,0^{\circ} \mathrm{C}$ no inverno, 1,9 ${ }^{\circ} \mathrm{C}$ na primavera e $3,4{ }^{\circ} \mathrm{C}$ no verão, aumentando a umidade relativa do ar em $4 \%$ a $7 \%$ e reduzindo a velocidade do vento nas estações do ano analisadas. No interior da mata, a temperatura mínima foi $0,2{ }^{\circ} \mathrm{C}$ mais alta no verão e $1,2^{\circ} \mathrm{C}$ mais baixa no inverno, quando comparada com o ambiente externo. $\mathrm{O}$ vinhedo, ao contrário, elevou a temperatura máxima de $0,5{ }^{\circ} \mathrm{C}$ a $1,0{ }^{\circ} \mathrm{C}$ e reduziu a umidade relativa do ar em $2 \%$, quando comparado com o ambiente-padrão do posto meteorológico. Palavras-chave: microclima, mata, vinhedo, temperatura do ar, umidade relativa, velocidade do vento.
\end{abstract}

\author{
ABSTRACT \\ SEAZONAL DIFERENCES AMONG MICROCLIMATIC VARIABLES FROM \\ ENVIRONMENTS OF FOREST INTERIOR, VINEYARD AND STANDARD \\ WEATHER STATION AT JUNDIAÍ, BRAZIL
}

Studies aiming the characterization of microclimatic variability are important for evaluating forest and vineyards management. Therefore microclimatic measurements of: air temperature, relative humidity and wind speed were taken, at Jundiaí, State of São Paulo, Brazil. The following environments were evaluated: semideciduous forest interior, 'Niagara Rosada' vineyard and standard weather station. Seazonal variation comparison was performed using daily data collected by automatic weather stations during the following months:August, 2000 (winter), October, 2000 (spring) and January, 2001 (summer). The internal microclimate was modified at semideciduous forest, with a decrease of maximum air temperature by $1.0^{\circ} \mathrm{C}, 1.9^{\circ} \mathrm{C}$ and $3.4^{\circ} \mathrm{C}$, respectively for winter, spring and summer; an increase of air relative humidity from $4-7 \%$, and a reduction of wind speed in all evaluated seasons. The minimum air temperature inside the forest was $0.2^{\circ} \mathrm{C}$ higher than at the standard weather station during summer, and $1.2{ }^{\circ} \mathrm{C}$ lower during winter. On the other hand, the vineyard lead to an increase of $0.5^{\circ} \mathrm{C}$ to $1.0^{\circ} \mathrm{C}$ on the maximum air temperature and to a decrease of $2 \%$ on the relative humidity when compared to standard weather station environment.

Key words: microclimates, forest, vineyard, air temperature, relative humidity, wind speed.

(1) Parte da dissertação de mestrado em Agricultura Tropical e Subtropical, área Gestão de Recursos Agroambientais, do primeiro autor, apresentada ao Instituto Agronômico (IAC), Campinas (SP). Recebido para publicação em 29 de outubro de 2001 e aceito em 3 de maio de 2002.

$\left({ }^{2}\right)$ Centro Avançado de Pesquisa Tecnológica do Agronegócio de Frutas, IAC, Caixa Postal 11, 13200-970 Jundiaí (SP).

( $)$ Com bolsa de produtividade científica do CNPq. 


\section{INTRODUÇÃO}

A cultura da videira é hoje a atividade agrícola mais importante no município de Jundiaí, ocupando uma área ao redor de 2.000 hectares, predominantemente com a variedade Niagara Rosada, que, somada a outras atividades rurais, como pastagens e reflorestamentos com eucalipto e pinus ocupa cerca de 12.000 hectares. Em contraste, as matas e outras coberturas naturais têm tido suas áreas amplamente reduzidas em função das atividades agrícolas e da expansão urbana, restando hoje algo em torno de 8.000 hectares de vegetação natural, restrita em sua maior parte à Serra do Japi, área de preservação permanente ${ }^{(4)}$.

As atividades humanas, tais como agricultura e silvicultura e conseqüentes distúrbios naturais, podem modificar o ambiente físico de um ecossistema por alteração do caráter estrutural. Dentre as modificações que o homem pode provocar no ambiente, a alteração no microclima talvez seja a mais importante e, no entanto, a menos estudada.

A importância do microclima em influenciar os processos ecológicos, tais como crescimento e regeneração de plantas, reciclagem de nutrientes e seleção de habitats de vida silvestre tornou-o um componente essencial da pesquisa ecológica corrente. Informações microclimáticas são, portanto, vitais para estudos no campo empírico, exercícios de modelagem teórica e tomadas de decisão de manejo (CHEN et al., 1999).

O microclima em vinhedos tem sido pouco avaliado. A maioria dos autores relata a influência do manejo da planta nos parâmetros microclimáticos. SMART (1985) fez uma revisão sobre os princípios de manipulação do microclima da copa da videira com implicações na produtividade e na qualidade do produto. Posteriormente, JACKSON e LOMBARD (1993) também relataram os efeitos de práticas de manejo na composição do vinho. PERCIVAL et al. (1994), em estudos da cultivar Riesling avaliaram a influência do espaçamento e remoção de folhas no microclima da copa. Pedro-Júnior et al. (1998) mostraram a influência da remoção de folhas de videira na ocorrência de doenças fúngicas foliares, por propiciar microclima favorável nas plantas mais enfolhadas.

No caso de ambiente interior de florestas e bosques, os estudos de caracterização e variabilidade microclimática têm sido relatados, principalmente, no Hemisfério Norte. Kittredge (1948) apresentou uma revisão com aspectos relativos ao microclima de florestas mostrando sua influência na temperatura e aspectos fisioecológicos das matas. GEIGER (1950) também apresentou revisão em que há diversos exemplos da influência de florestas e bosques sobre o microclima em seu interior.

$\mathrm{O}$ efeito atenuante das florestas nos valores máximos e mínimos da temperatura do ar, umidade relativa e velocidade do vento, nas diferentes estações do ano, foi verificado por vários autores (SPURr e BARNES, 1973; SMITH, 1975; YosHINO, 1975).

No Brasil, Seitz (1976) avaliou a influência de bosques de pinus e araucária sobre a temperatura e umidade do ar. Mello et al. (1988), no Horto Florestal de São Paulo, concluíram que as bacias hidrográficas próximas à reserva florestal promoveram interferência nos mecanismos microclimáticos. CESTARO (1988) avaliou a variação estacional da temperatura e umidade do ar em mata de araucária no Rio Grande do Sul. CABRAL e Miranda (1993), em cultivo de seringueira na região de Manaus encontraram variações até de $10{ }^{\circ} \mathrm{C}$ com o ambiente externo. Mais tarde, CABRAL et al. (1996), avaliando os perfis de temperatura em florestas na Amazônia, detectaram variações na temperatura até de $4,5^{\circ} \mathrm{C}$. SCHumacher (1992), em talhões de eucalipto, na região de Piracicaba (SP), mostrou diferenças na amplitude térmica de $13^{\circ} \mathrm{C} \mathrm{e} 10^{\circ} \mathrm{C}$, respectivamente, no verão e inverno. Culf et al. (1996), em Marabá (PA), obtiveram reduções até de $3{ }^{\circ} \mathrm{C}$ na temperatura do ar no interior de florestas e, mais recentemente, Pezzopane (2001) verificou diferenças significativas de temperatura e umidade do ar entre uma mata semidecídua secundária e uma área aberta adjacente em Viçosa (MG).

Pelo fato de os estudos de caracterização da variabilidade microclimática serem essenciais na avaliação de alternativas silviculturais (CHEN et al., 1999) e no manejo e condução de vinhedos (SMART, 1985), desenvolveu-se este trabalho a fim de caracterizar, na região de Jundiaí (SP), a variação estacional nos ambientes de interior de mata e de vinhedo dos parâmetros microclimáticos: temperatura e umidade relativa do ar e velocidade do vento.

(4) Dados do projeto Levantamento de Unidades de Produção Agropecuária (LUPA) - Estatísticas Agrícolas - Secretaria de Agricultura e Abastecimento do Estado de São Paulo, 1995/96. 


\section{MATERIAL E MÉTODOS}

O trabalho foi realizado na Estação Experimental de Agronomia do Instituto Agronômico (IAC), localizada no município de Jundiaí, sendo as coordenadas geográficas: latitude $23^{\circ} 06^{\prime} \mathrm{S}$, longitude $46^{\circ} 55^{\prime} \mathrm{W}$, com altitudes variando de 680 a 760 metros. $\mathrm{O}$ posto agrometeorológico encontra-se a $730 \mathrm{~m}$ de altitude; o vinhedo e a mata a 745 e $735 \mathrm{~m}$ respectivamente - dados obtidos na carta 1/10.000. Predominam no local os relevos ondulado e fortemente ondulado e declividades acentuadas (acima de 12\%) em $80 \%$ da área total (Melo e Lombardi-Neto, 1998).

A mata existente na estação experimental é um fragmento remanescente da floresta mesófila semidecídua; está dividida em subfragmentos, e o maior deles, onde foram instalados os equipamentos, ocupa uma área de aproximadamente 35 hectares, apresentando alta diversidade florística com predominância de Caesalpiniaceae, Fabaceae, Mimosaceae (Leguminosae), Euphorbiaceae, Lauraceae, Lecythidaceae, Meliaceae e Myrtaceae (HERNANDES, 1996).

O vinhedo utilizado é formado por uma quadra de $384 \mathrm{~m}^{2}$ da variedade Niagara Rosada, cultivada no sistema de espaldeira, com três fios de arame e poda em cordão esporonado, como descrito por INGLEZ de SouZA et al. (1969), e espaçamento de $1 \mathrm{~m}$ entre plantas e $2 \mathrm{~m}$ entre linhas utilizando, nas entrelinhas, cobertura com capim seco.

Caracterizaram-se a variação estacional da temperatura e umidade relativa do ar e a velocidade do vento, utilizando-se os dados obtidos por estações meteorológicas automáticas, na mata e no vinhedo ${ }^{(5)}$, no posto meteorológico ${ }^{(6)}$ em agosto e outubro de 2000 e janeiro de 2001, representando as condições de inverno, primavera e verão respectivamente. Determinaram-se a temperatura e a umidade relativa do ar a $1,7 \mathrm{~m}$ e a velocidade do vento a $2 \mathrm{~m}$ de altura.

Os valores médios diários obtidos foram submetidos à análise da variância para dados pareados (SokAl e RohlF, 1969; BeIGUELMAN, 1996), para comparação entre os diferentes ambientes analisados; a significância foi verificada pelo teste F.

\section{RESULTADOS E DISCUSSÃO}

A variação diária e o resumo das comparações entre os valores de temperatura do ar máxima e mínima, amplitude térmica, umidade relativa do ar mínima e média e velocidade do vento para os meses representativos das diferentes estações do ano, nos ambientes de interior de mata, vinhedo e posto meteorológico são mostrados nas figuras 1 a 3 e no quadro 1 .

\subsection{Temperatura máxima do ar}

Observa-se nas figuras 1a, 2a e 3a e no quadro 1 que a temperatura máxima do ar foi sempre menor no interior da mata, quando comparada ao vinhedo e ao posto meteorológico, independentemente da estação do ano. Comparando-se os valores obtidos na mata com os do posto meteorológico, obtiveramse diferenças de $1,0^{\circ} \mathrm{C}$ no inverno, $3,4^{\circ} \mathrm{C}$ e $1,9^{\circ} \mathrm{C}$ na primavera, enquanto a comparação entre as temperaturas máximas na mata e no vinhedo mostrou valores de $2{ }^{\circ} \mathrm{C}$ no inverno, $3,9^{\circ} \mathrm{C}$ no verão e $2,9^{\circ} \mathrm{C}$ na primavera.

Entre o posto meteorológico e o vinhedo, a diferença na temperatura máxima do ar, apesar de significativa, foi menor; registraram-se valores sempre inferiores no posto meteorológico, em todas as estações do ano analisadas. Ao contrário do que ocorreu entre o interior da mata e os ambientes externos, quando se compararam o posto meteorológico e o vinhedo, a diferença obtida foi menor no verão que no inverno, com valores de 1,0 ${ }^{\circ} \mathrm{C}$ no inverno e na primavera e de $0,5^{\circ} \mathrm{C}$ no verão.

Outros autores também verificaram valores de temperatura máxima do ar inferiores no interior de florestas quando comparados com ambientes externos da ordem de $2,0^{\circ} \mathrm{C}$ a $5,0^{\circ} \mathrm{C}$ em diferentes estações do ano (SPURr e BARNES, 1973; CESTARO, 1988; CARLSON e Groot, 1997; Morecroft et al., 1998).

Esses valores são semelhantes aos obtidos no presente estudo, mostrando que as florestas decíduas ou semidecíduas exercem importante efeito atenuador sobre a temperatura máxima do ar, principalmente no período mais quente do ano, quando comparada com a dos ambientes abertos. Esse fenômeno está relacionado com a barreira proporcionada pelo dossel das copas das árvores que impede a penetração, no interior da mata, da maior parte da radiação solar durante o dia. Essa menor quantidade de radiação solar incidente implica menor aquecimento do solo e, conseqüentemente, menor emissão de radiação de onda longa e menor aquecimento do ar no espaço entre o solo e as copas das árvores (SMITH, 1975).

$\left(^{5}\right)$ DAVIS INSTRUMENTS CORP, com software GroWeatherlink versão 1.0.

(6) ENGESPAÇO, com software PC208w, Campbell Scientific. 

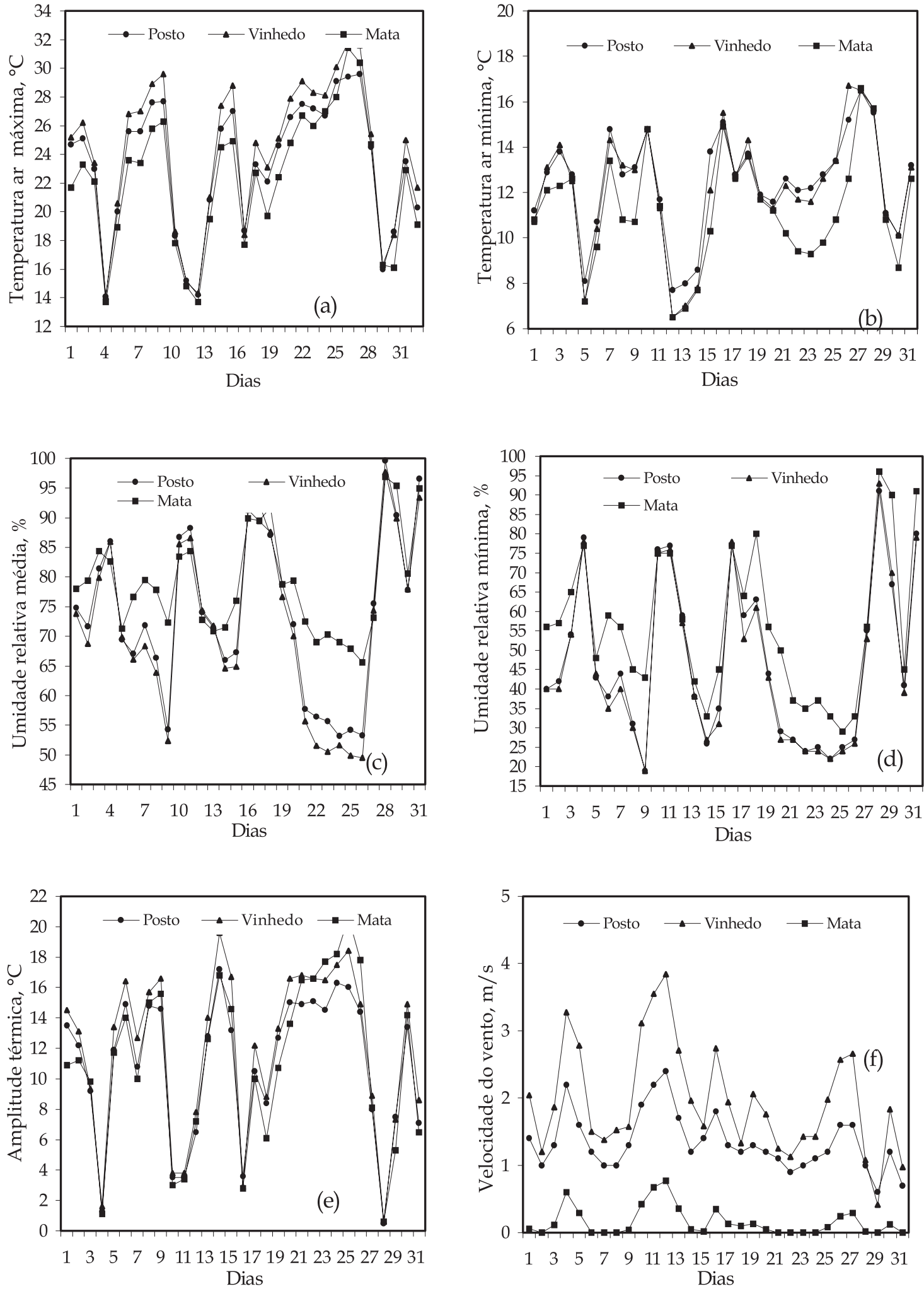

Figura 1. Variação diária da temperatura do ar máxima (a) e mínima (b), umidade relativa do ar média (c) e mínima (d), amplitude térmica (e) e velocidade do vento (f), em ambientes de mata, vinhedo e posto meteorológico em agosto (inverno) de 2000, em Jundiaí (SP). 

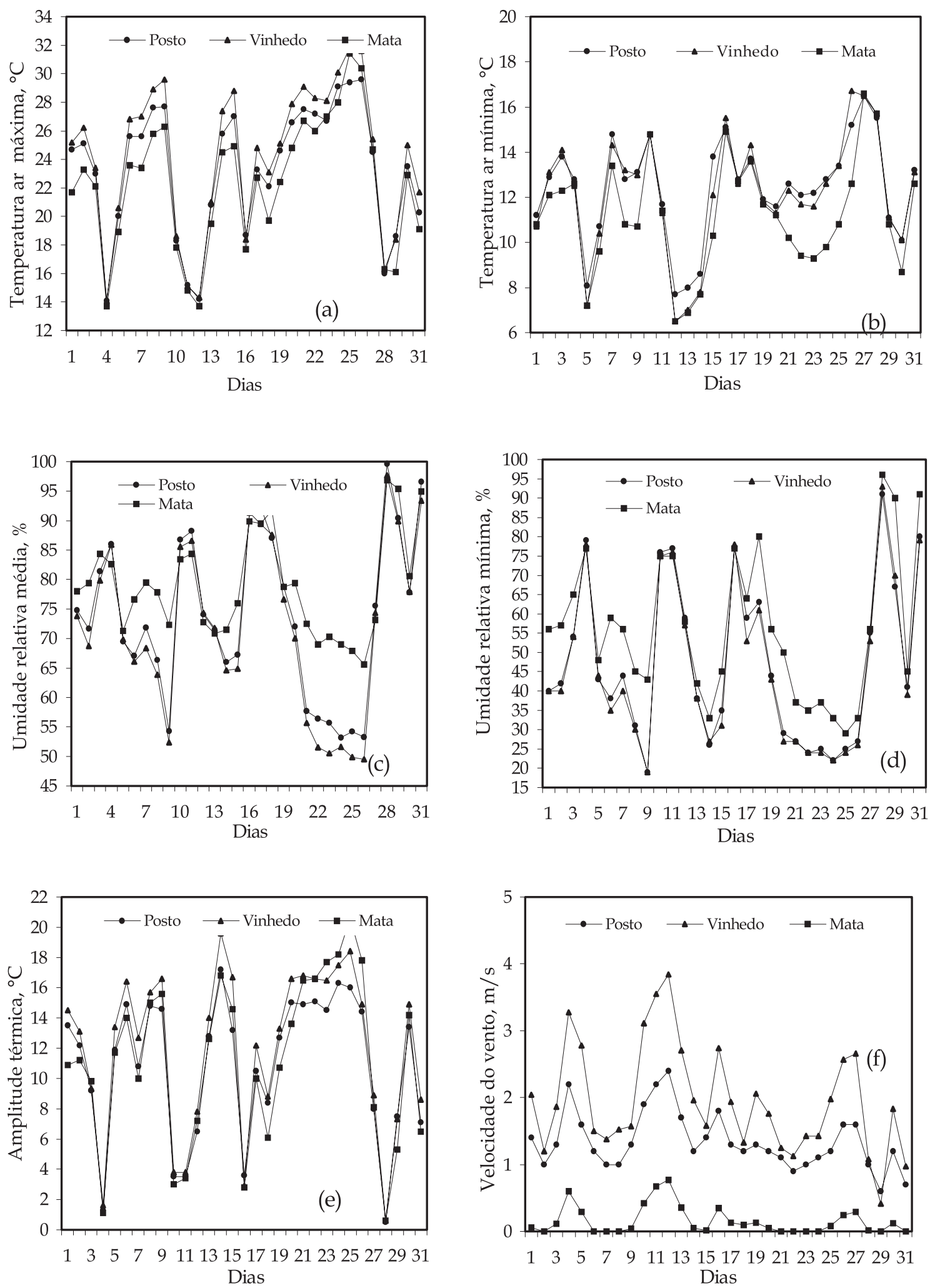

Figura 2. Variação diária da temperatura do ar máxima (a) e mínima (b), umidade relativa do ar média (c) e mínima (d), amplitude térmica (e) e velocidade do vento (f), em ambientes de mata, vinhedo e posto meteorológico em outubro (primavera) de 2000, em Jundiaí (SP). 

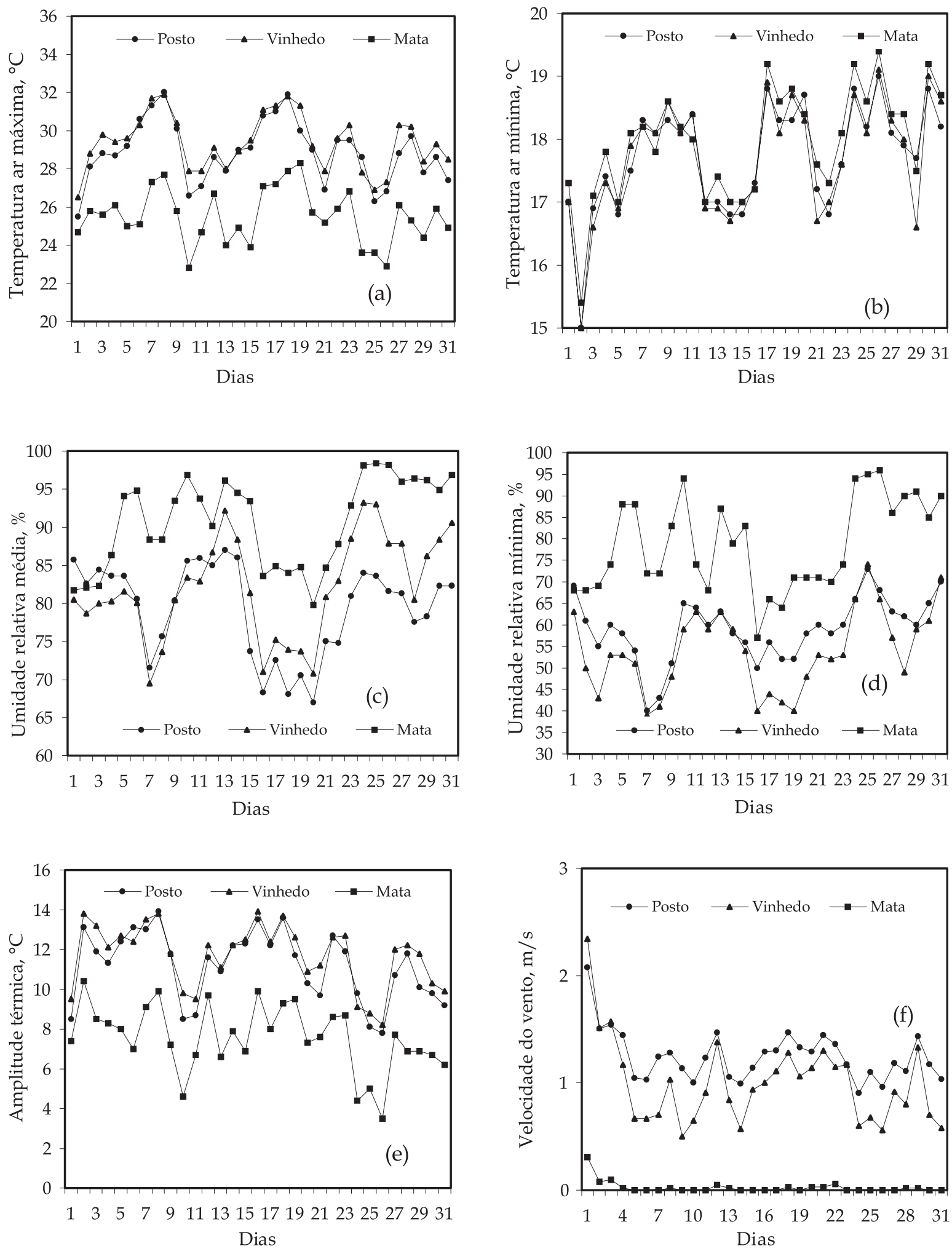

Figura 3. Variação diária da temperatura do ar máxima (a) e mínima (b), umidade relativa do ar média (c) e mínima (d), amplitude térmica (e) e velocidade do vento (f), em ambientes de mata, vinhedo e posto meteorológico em janeiro (verão) de 2001, em Jundiaí (SP). 
Diferenças Estacionais entre Variáveis Microclimáticas em Jundiaí (SP)

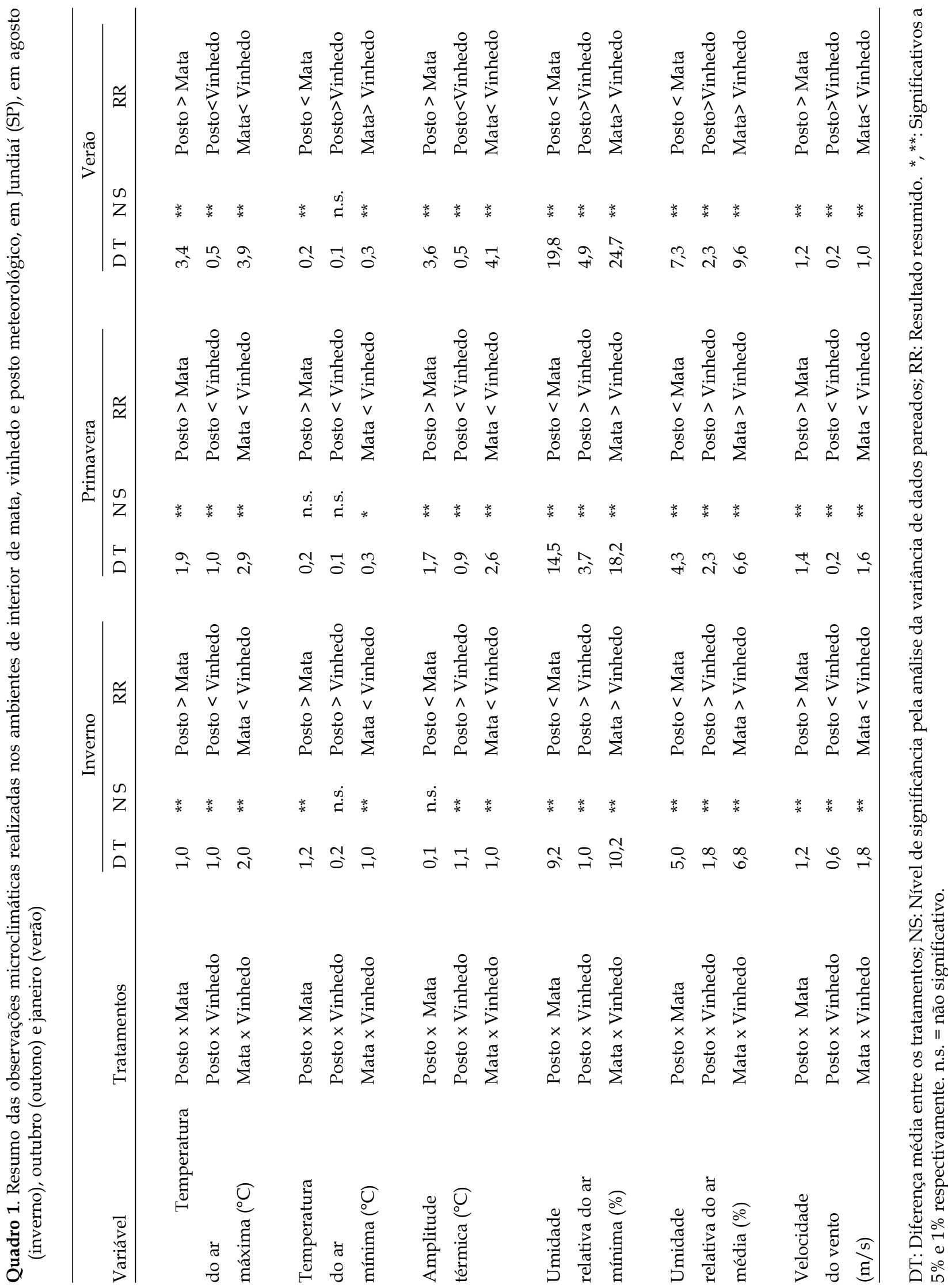


A capacidade de atenuação da temperatura máxima do ar, no entanto, é reduzida no inverno e na primavera, provavelmente porque a mata local é um fragmento da floresta mesófila semidecídua, caracteristicamente sazonal, com um período de perda de folhas que, em geral, vai de abril a setembro (Morellato 1992). Esse período corresponde à época mais fria e seca do ano e este comportamento induz à diminuição da evapotranspiração pela perda da área foliar, possibilitando às plantas condições de enfrentar o estresse hídrico a que estarão sujeitas.

A perda de parte das folhas no período mais frio e mais seco do ano prejudica, sensivelmente, a cobertura do dossel da mata, diminuindo a eficiência de absorção da radiação solar que chega no interior da mata, atenuando a diferença na temperatura máxima entre o interior da mata e os ambientes externos.

Quanto ao vinhedo, o fato de os valores de temperatura média máxima do ar serem mais elevados, pode estar relacionado com a menor capacidade de absorção da radiação solar proporcionada pelas copas das videiras e, também, pela cobertura do solo feita com capim seco (mulching). Como as videiras são plantadas em linhas paralelas, espaçadas de $2 \mathrm{~m}$, e permanecem sem folhas por períodos significativos, desde a dormência até a formação completa da copa e, ainda, sofrem desbastes contínuos de folhas e ramos adventícios durante o período vegetativo, permitem que grande parte da radiação solar direta atinja a cobertura de capim, que por sua vez tem sua superfície aquecida rapidamente. Como a palha seca tem baixa condutividade térmica a quantidade de calor transmitido ao solo é pequena. Em conseqüência, o ar próximo à superfície se aquece mais rapidamente, promovendo a ocorrência de temperaturas máximas mais elevadas na camada de ar próxima às videiras (ОKE, 1978).

Os resultados obtidos neste trabalho mostraram, portanto, que a mata semidecídua de planalto paulista exerce importante efeito atenuador e que, ao contrário, o ambiente do vinhedo eleva a temperatura máxima do ar, quando comparados com o ambiente-padrão do posto meteorológico e, ainda, que esses efeitos são menos sensíveis no período mais seco e mais frio do ano.

\subsection{Temperatura minima do ar}

A temperatura mínima do ar apresenta diferenças entre as estações do ano nos ambientes estudados (Figuras $1 b, 2 b$ e $3 b$ e Quadro 1). No inverno, a temperatura mínima média foi $1,2^{\circ} \mathrm{C}$ e $1,0^{\circ} \mathrm{C}$ menor no interior da mata que no posto meteorológico e no vinhedo respectivamente. Na primavera, essa diferença diminuiu para $0,2^{\circ} \mathrm{C}$ e $0,3^{\circ} \mathrm{C}$, mantendose inferior no interior da mata; no verão, entretanto, ocorreu uma inversão: a temperatura mínima média do ar apresentou valores de $0,2{ }^{\circ} \mathrm{C}$ e $0,3{ }^{\circ} \mathrm{C}$ mais elevados no interior da mata que no posto meteorológico e no vinhedo respectivamente.

Comparando-se os dados do posto meteorológico e do vinhedo, verifica-se que as diferenças encontradas não foram significativas em nenhuma das estações do ano analisadas: $0,2^{\circ} \mathrm{Ce} 0,1^{\circ} \mathrm{C}$ maior no posto meteorológico que no vinhedo no inverno e no verão, respectivamente, $\mathrm{e}, 1^{\circ} \mathrm{C}$ menor no posto meteorológico na primavera.

Valores de temperatura mínima média do ar mais elevados no interior de florestas em diferentes estações do ano são relatados na ordem de $1,5^{\circ} \mathrm{C}$ a $3,2{ }^{\circ} \mathrm{C}$ por Spurr e Barnes (1973); Stoutjesdijk e Barkman (1992); HaWke e Wedderburn (1994); CARLSON e Groot (1997), todos trabalhando em países de inverno rigoroso e em plantios de pinheiros.

No Brasil, CESTARO (1988), em estudo microclimático em interior de mata de araucária, obteve resultados de temperatura mínima do ar inferiores aos de gramado, ou seja, $1,0^{\circ} \mathrm{C}$ nos meses de inverno.

Os resultados deste trabalho também mostram que a temperatura mínima do ar foi inferior apenas no interior da mata se comparado aos ambientes externos no período mais frio do ano. Isso, provavelmente, pode estar relacionado com o caráter semidecíduo da vegetação arbórea local.

Os resultados obtidos revelam, portanto, que a mata semidecídua de planalto paulista exerce o poder de elevar a temperatura mínima média do ar em relação ao ambiente externo no verão, e perde essa capacidade nos meses mais frios do ano, no inverno e na primavera, em função da característica fenológica sazonal.

\subsection{Amplitude térmica}

A amplitude térmica foi quase sempre menor no interior da mata que no posto meteorológico ou no vinhedo, independentemente da estação do ano (Figuras 1e, 2e e 3e). Exceção ocorreu apenas no inverno, cuja amplitude térmica foi maior na mata que no posto meteorológico (Quadro 1), no entanto, por valor não significativo. Nota-se, também, que a diferença de amplitude térmica entre o interior da mata e os ambientes externos foi maior nos meses mais quentes do ano.

No inverno, a diferença foi de $1,0^{\circ} \mathrm{C}$ menor na mata que no vinhedo; na primavera, a amplitude 
térmica foi $1,7^{\circ} \mathrm{C}$ e $2,6^{\circ} \mathrm{C}$ mais elevada no posto meteorológico e no vinhedo respectivamente; no verão, essa diferença subiu para $3,6^{\circ} \mathrm{C}$ e $4,1^{\circ} \mathrm{C}$.

A diferença de amplitude térmica entre o posto meteorológico e o vinhedo, ao contrário, foi menor nos meses mais quentes e sempre menor no posto que no vinhedo: $1,1^{\circ} \mathrm{C}$ no inverno, $0,9^{\circ} \mathrm{C}$ na primavera e $0,5^{\circ} \mathrm{C}$ no verão.

Valores de amplitude térmica de $3,0{ }^{\circ} \mathrm{C}$ a $7,0{ }^{\circ} \mathrm{C}$ menores no interior de florestas em diferentes estações do ano são relatados na literatura (SPURR e BARNES, 1973; SCHUMACHER, 1992; Culf et al., 1996; Carlson e Groot, 1997).

Os dados obtidos neste estudo demonstram que as variações da amplitude térmica estão mais relacionadas às diferenças existentes entre as temperaturas máximas que as mínimas entre os ambientes. Dessa maneira, a amplitude térmica é sempre menor no interior da mata e maior no vinhedo que no ambiente-padrão do posto meteorológico. Além disso, sofre influência das características fenológicas específicas da vegetação arbórea local, que promovem uma variação sazonal, conforme discutido anteriormente.

\subsection{Umidade relativa mínima do ar}

A umidade relativa mínima do ar (Figuras 1d, 2d e 3d e Quadro 1) foi significativamente maior no interior da mata que no posto meteorológico, ou no vinhedo, independentemente da estação do ano, e as maiores diferenças ocorreram nos meses mais quentes. No inverno, a diferença na umidade relativa mínima do ar foi de 9,2\% e 10,2\%; na primavera, $14,5 \%$ e $18,2 \%$ e no verão, $19,8 \%$ e $24,7 \%$, sempre menor na mata que no posto meteorológico ou no vinhedo respectivamente.

Entre o posto meteorológico e o vinhedo, a diferença, apesar de significativa, foi muito menor e a umidade relativa mínima foi sempre mais elevada no posto meteorológico. Também nesse caso, a diferença foi maior nos meses mais quentes do ano. No inverno, a diferença foi de $1 \%$; na primavera, 3,7\% e no verão, a umidade relativa mínima do ar foi $4,9 \%$ maior no posto meteorológico que no vinhedo.

A umidade relativa mínima do ar tem sido utilizada como o parâmetro que permite melhor comparação entre ambientes, pois, como observado por KitTREDGE (1948), a umidade relativa máxima, normalmente aproxima-se de $100 \%$ durante noite e não é distintiva entre ambientes; valores mínimos, porém, que usualmente ocorrem no início da tarde podem ser muito mais precisos.
Diferenças significativas e elevadas de umidade relativa mínima do ar, da ordem de $12 \%$ a $15 \%$, entre o interior de florestas e ambientes externos, foram relatados por diferentes autores (CESTARO, 1988; CHEN et al., 1993).

Os dados relatados na literatura, bem como aqueles obtidos neste trabalho, demonstram a capacidade da cobertura florestal, nesse caso de floresta semidecídua, em manter a umidade relativa mínima do ar mais elevada, principalmente nos períodos mais quentes e úmidos do ano. Essa capacidade está, provavelmente, relacionada à menor temperatura e à menor movimentação do ar no interior da mata que favorecem que as condições ali permaneçam mais estáveis estando, entretanto, também sujeita à variação sazonal característica da vegetação local (SEITZ, 1976).

\subsection{Umidade relativa média do ar}

Nas figuras $1 c$, 2c e $3 c$ e no quadro 1 , pode-se verificar que a umidade relativa média foi significativamente maior no interior da mata que no posto meteorológico e no vinhedo. Quando se analisou o conjunto de dados independentemente da estação do ano, no entanto, verificaram-se diferenças entre elas. No inverno, a umidade relativa média do ar foi $5 \%$ e $6,8 \%$ mais elevada no interior da mata que no posto meteorológico e no vinhedo respectivamente, enquanto na primavera essa diferença diminuiu para $4,3 \%$ e $6,6 \%$. No verão, a diferença na umidade relativa média do ar alcançou valores de $7,3 \%$ e $9,6 \%$ mais elevados no interior da mata que no posto meteorológico e no vinhedo.

A umidade relativa média foi sempre mais elevada no posto meteorológico que no vinhedo e, apesar de ser estatisticamente significativa, a diferença foi muito menor e praticamente não variou entre as estações do ano (Quadro 1). No inverno, a diferença foi de $1,8 \%$; na primavera e no verão, $2,3 \%$ maior no posto meteorológico que no vinhedo.

Diversos fatores que ocorrem no interior da mata, tais como, a redução na radiação direta, na temperatura máxima e na velocidade do vento, tendem a produzir valores de umidade relativa mais altos no interior de florestas, especialmente durante os meses de transpiração máxima no verão (SMiтH, 1975).

CHEN et al. (1999) mostraram que no Sul de Washington (EUA), no verão, durante o dia, a umidade relativa atingiu valores até de 7,5\% e, à noite, 5,8\% mais elevados dentro da floresta que na clareira. 
Os dados obtidos neste trabalho e os relatados na literatura permitem verificar que, exceto sob condições específicas de inverno no Hemisfério Norte, as florestas, dentre elas a semidecídua de planalto paulista, exercem efeito significativo sobre a umidade relativa do ar, mantendo-a sempre mais elevada em seu interior.

\subsection{Velocidade do vento}

Verifica-se, pelas figuras $1 \mathrm{f}, 2 \mathrm{f}$ e $3 \mathrm{f}$ e no quadro 1 que a velocidade do vento diferiu significativamente entre os três ambientes analisados, e foi sempre menor no interior da mata que no posto meteorológico e no vinhedo, não havendo, entretanto, diferença marcante entre as estações do ano. No inverno, a velocidade do vento foi $1,2 \mathrm{~m} / \mathrm{s} \mathrm{e}$ $1,8 \mathrm{~m} / \mathrm{s}$ inferior no interior da mata; na primavera, a diferença foi de $1,4 \mathrm{~m} / \mathrm{s}$ e $1,6 \mathrm{~m} / \mathrm{s}$, e no verão, a velocidade do vento foi de $1,2 \mathrm{~m} / \mathrm{s}$ e $1,0 \mathrm{~m} / \mathrm{s}$ menor no interior da mata que no posto meteorológico e no vinhedo respectivamente.

Entre o posto meteorológico e o vinhedo, a diferença na velocidade do vento, apesar de significativa, foi menor e apresentou pequena inversão entre as estações do ano. No inverno, a velocidade do vento foi $0,6 \mathrm{~m} / \mathrm{s}$ menor no posto meteorológico que no vinhedo; na primavera, $0,2 \mathrm{~m} /$ $\mathrm{s}$ também menor no posto meteorológico. No verão, entretanto, a diferença foi de $0,2 \mathrm{~m} / \mathrm{s}$ menor no vinhedo que no posto meteorológico.

Em valores absolutos, a velocidade média do vento no inverno variou no interior da mata de $0,0 \mathrm{a}$ $0,77 \mathrm{~m} / \mathrm{s}$; no vinhedo, de 0,41 a $3,84 \mathrm{~m} / \mathrm{s}$ e no posto meteorológico, de 0,60 a 2,40 m/s. Na primavera, a variação foi de 0,0 a $0,63 \mathrm{~m} / \mathrm{s}$ no interior da mata; 0,63 a $3,12 \mathrm{~m} / \mathrm{s}$ no vinhedo e 0,91 a $2,46 \mathrm{~m} / \mathrm{s}$ no posto meteorológico. No verão, a velocidade média do vento no interior da mata variou de 0,0 a $0,31 \mathrm{~m} / \mathrm{s}$; no vinhedo, de 0,50 a $2,34 \mathrm{~m} / \mathrm{s}$ e no posto meteorológico, de 0,90 a $2,08 \mathrm{~m} / \mathrm{s}$.

Em valores relativos, as velocidades médias do vento observadas no interior da mata foram menores $88 \%, 93 \%$ e $98 \%$ que as do posto meteorológico e $92 \%$, 93\% e $97 \%$ que as do vinhedo, respectivamente, no inverno, na primavera e no verão. Já as velocidades observadas no vinhedo foram de $45 \%, 10 \%$ e $21 \%$ maiores que no posto meteorológico, nas respectivas estações.

A maior redução relativa da velocidade do vento no interior da mata, no verão, deve-se ao maior enfolhamento do dossel das árvores e da vegetação do sub-bosque neste período, o que aumenta a eficiência da barreira imposta à movimentação do ar.
A diferença entre o inverno e o verão, na velocidade do vento, entre o vinhedo e o posto meteorológico mostrada no quadro 1 , pode ser explicada pelas características da videira e pelo sistema de condução do vinhedo. Cultivada no sistema de espaldeiras paralelas distanciadas de 2 metros, a videira é submetida à poda no final do inverno-início da primavera; seus ramos são conduzidos verticalmente amarrados nos arames, tendo seus ápices decepados quando ultrapassam aproximadamente $20 \mathrm{~cm}$ acima do último arame. Dessa maneira, em plena vegetação, no verão, a copa da videira alcançará em média $1,8 \mathrm{~m}$ de altura, proporcionando uma barreira que pode bloquear, em parte, a movimentação do ar, diminuindo a velocidade do vento no vinhedo.

A redução da velocidade do vento no interior de florestas é fenômeno amplamente relatado na literatura. SмIтH (1975) ao relatar dados de médias mensais de velocidade do vento no interior de uma floresta mista de carvalhos e decíduas no Tenessee (EUA), mostrou que em todos os meses do ano a velocidade do vento na floresta foi significativamente menor, com valores de $88 \%$ de redução da velocidade do vento no inverno e $98 \%$ no verão, em relação ao local aberto.

Medições de velocidade do vento no interior de florestas, comparadas às de ambientes externos realizadas por vários autores revelaram um efeito de amortecimento de 70\% a 85\% (Yoshino, 1975; Cestaro, 1988; Chen et al., 1993; HaWKe e WedDERburn, 1994; Morecroft et al., 1998).

Os dados obtidos neste trabalho são coerentes com os encontrados na literatura; observa-se que a mata semidecídua, principalmente no verão, é capaz de diminuir a circulação de ar em seu interior, reduzindo a velocidade do vento. Observa-se, também, que, em plena vegetação, no verão, a videira bloqueia o movimento do ar, diminuindo a velocidade do vento no vinhedo.

\section{CONCLUSÕES}

1. A mata semidecídua de planalto paulista exerceu influência sobre o microclima em seu interior, reduzindo a temperatura do ar, elevando a umidade relativa e diminuindo a velocidade do vento, quando comparada com o ambiente-padrão do posto meteorológico.

2. O vinhedo influiu no microclima, com tendência para elevar a temperatura do ar e a amplitude térmica e reduzir a umidade relativa do ar, em relação ao posto meteorológico e à mata. 
3. A temperatura máxima do ar no interior da mata foi mais baixa em $1^{\circ} \mathrm{C}$ no inverno, $1,9^{\circ} \mathrm{C}$ na primavera e $3,4^{\circ} \mathrm{C}$ no verão, em relação ao posto meteorológico.

4. As diferenças de temperatura mínima entre a mata e o posto meteorológico foram menos marcantes, variando nas estações do ano entre 0,2 ${ }^{\circ} \mathrm{C}$ maior na mata, no verão, e $1,2^{\circ} \mathrm{C}$ maior no posto meteorológico, no inverno.

5. As temperaturas máximas no vinhedo foram superiores às do posto meteorológico nas diferentes estações do ano, variando de $0,5^{\circ} \mathrm{C}$ a $1,0^{\circ} \mathrm{C}$, enquanto as temperaturas mínimas não diferiram estatisticamente entre os dois ambientes nas estações analisadas.

6. A umidade relativa do ar foi maior no interior da mata, em $4 \%$ a $7 \%$, e menor no vinhedo, aproximadamente $2 \%$, que no posto meteorológico.

7. O comportamento fenológico sazonal da mata semidecídua, no período de perda das folhas, influiu no microclima, diminuindo as diferenças entre os valores de temperatura e de umidade relativa do ar obtidos na mata, em comparação com o posto meteorológico e o vinhedo.

\section{REFERÊNCIAS BIBLIOGRÁFICAS}

BEIGUELMAN, B. Curso prático de Bioestatística. 4.ed. Ribeirão Preto: Sociedade Brasileira de Genética, 1996. 242p.

CABRAL, O.M.R.; McWILLIAN, A.L.C.; ROBERTS, J.M. In-canopy microclimate of Amazonian forest and estimates of transpiration. In: GASH, J.H.C.; NOBRE, C.A.; ROBERTS, J.M.; VICTORIA, R.L. Amazonian deforestation and climate. New York: John Wiley \& Sons, 1996, p.207-220.

CABRAL, O.M.R.; MIRANDA, A.C. Parâmetros micrometeorológicos relacionados às doenças da seringueira em Manaus (AM). Fitopatologia Brasileira, Brasília, v.18, n.3, p.365-370, 1993.

CARLSON, D.W.; GROOT, A. Microclimate of clear-cut, forest interior, and small openings in trembling aspen forest. Agricultural and Forest Meteorology, Amsterdam, v.87, p.313-329, 1997.

CESTARO, L.A. Estudo microclimático do interior de uma mata de araucária na Estação Ecológica de Aracuri, Esmeralda , RS. Árvore, v.12, n.1, p.41-57, 1988.

CHEN, J.; FRANKLIN, J.F.; SPIES, T.A. Contrasting microclimates among clearcut, edge, and interior of old-growth Douglas-fir forest. Agricultural and Forest Meteorology, Amsterdam, v.63, p.219-237. 1993.

CHEN, J.; SAUNDERS, S.C.; CROW, T.R.; NAIMAN, R.J.; BROSOFSKE. K.D.; MROZ, G.D.; BROOKSHIRE,
B.L.; FRANKLIN, J.F. Microclimate in forest ecossistem and landscape ecology. Bioscience, Washington, v.49, p.288-297, 1999.

CULF, A.D.; ESTEVES, J.L.; MARQUES-FILHO, A. de O.; ROCHA, H.R. da. Radiation, temperature and humidity over forest and pasture in Amazonian. In: GASH, J.H.C.; NOBRE, C.A.; ROBERTS, J.M.; VICTORIA, R.L. Amazonian deforestation and climate. New York: John Wiley \& Sons, 1996. p.175-191.

GEIGER, R. The climate near the ground. $2^{\text {nd }}$ ed. Cambridge, Massachusets,U.S.A: Harvard University Printing Office, 1950. 482p.

HAWKE, M.F.; WEDDERBURN, M.E. Microclimate changes under Pinus radiata agroforestry regimes in New Zealand. Agricultural and Forest Meteorology, Amsterdam, v.71, p.133-145, 1994.

HERNANDES, J.L. Caracterização da vegetação arbórea nativa da Estação Experimental de Jundiaí. In: CONGRESSO DA SOCIEDADE BOTÂNICA DESÃO PAULO, 11., 1996, São Carlos. Resumos... São Carlos: Sociedade Botânica de São Paulo, 1996. p.85.

INGLEZ DE SOUSA, J.S.; PINHEIRO, E.D.; AMARO, A.A. Uvas para o Brasil. São Paulo: Biblioteca Agronômica Melhoramentos, 1969. 454p.

JACKSON, D.I.; LOMBARD, P.B. Environmental and management practices affecting grape composition and wine quality. American Journal of Enology and Viticulture. Davis, v.44, n.4, p.409-430, 1993.

KITTREDGE, J. Forest influence: the effects of wood vegetation on climate, water and soil, with applications to the conservation of water and control of floods and erosion. New York: MacGraw-Hill, 1948. 394p.

MELLO, M.H. de A.; OLIVEIRA, M.C. de; NUNES, L.H.; GARCIA, A.D. Características microclimáticas de primavera-verão, no Horto Florestal (São Paulo). Acta Botânica Brasileira, v.1, n.2 (suplemento), p.263-273, 1988.

MELO, A.R.; LOMBARDI-NETO, F. Planejamento agroambiental da Estação Experimental de Jundiaí. In: CONGRESSO BRASILEIRO DE ENGENHARIA AGRÍCOLA, 27., 1998, Poços de Caldas. Anais... Lavras: SBEA/UFLA, 1998. p.389-391.

MORECROFT, M.D.; TAYLOR, M.E.; OLIVER, H.R. Air and soil microclimates of deciduous woodland compared to an a open site. Agricultural and Forest Meteorology, Amsterdam, v.90, n.1-2, p.141-156, 1998.

MORELLATO, L.P.C. (Org.) História natural da Serra do Japi: Ecologia e preservação de uma área florestal no sudeste do Brasil. Campinas: UNICAMP/FAPESP, 1992. 321p.

OKE, T.R. Boundary layer climates. London: Willian Clowes and Sons, 1978. 372p. 
PEDRO-JÚNIOR, M.J.; RIBEIRO, I.J.A.; MARTINS, F.P. Microclima condicionado pela remoção de folhas e ocorrência de antracnose, míldio e mancha-das-folhas na videira 'Niagara Rosada'. Summa Phytopathologica, Jaguariúna: v.24, n.2, p.151-156, 1998.

PERCIVAL, D.C.; FISHER, K.H.; SULLIVAN, J.A. Use of fruit zone leaf removal with Vitis-vinifera L., cV Riesling grapevines.1. Effects on canopy structure, microclimate, bud survival, shoot density, and vine vigor. American Journal of enology and viticulture, Davis, v.45, n.2, p.123-132, 1994.

PEZZOPANE, J.E.M. Caracterização microclimática, ecofisiológica e fitossociológica em uma floresta estacional semidecidual secundária, em Viçosa, MG. 2001. 225f. Tese (Doutorado em Ciências Florestais) - Universidade Federal de Viçosa.

SCHUMACHER, M.V. Aspectos da ciclagem de nutrientes e do microclima em talhões de Eucalyptus camaldulensis Dehnh, E. grandis Hill ex Maiden e E. torelliana F. Muell. 1992. 87f. Dissertação (Mestrado em Ciências Florestais) - Escola Superior de Agronomia "Luiz de Queiroz", Universidade de São Paulo, Piracicaba.
SEITZ, R.A. Estudo da variação da radiação solar, temperatura e unidade relativa do ar no interior de uma mata de Araucaria angustifolia em relação ao terreno livre. Floresta, n.7, p.36-45, 1976.

SMART, R.E. Principles of grapevine canopy microclimate manipulation with implications for yield and quality. American Journal of Enology and Viticulture, Davis, v.36, n.3, p.230-239, 1985.

SMITH, K. Principles of applied climatology. Berkshire, England: McGraw-Hill , 1975. 233p.

SOKAL, R.R.; ROHLF, F.J. Biometry. San Francisco: W.H. Freeman , 1969. 776p.

SPURR, S.H.; BARNES, B.V. Forest Ecology. New York: Ronald Press, 1973. 571p.

STOUTJESDIJK, P.H.; BARKMAN, J.J. Microclimate, Vegetation and Fauna: the microclimate of forests. Knivsta, Sweden: Opulus Press, 1992. 216p.

YOSHINO, M.M. Climate in a small area: an introduction to local meteorology. Tokio: University of Tokio Press, 1975. 549p. 